\title{
An underactive hypothalamo-pituitary-adrenal axis in a shift worker with chronic fatigue syndrome
}

\author{
UNIVERSITY OF BELGRADE \\ SCHOOL OF MEDICINE

\section{Clinic for endocrinology, \\ Diabetes and metabolic diseases \\ Clinical Center of Serbia \\ School of Medicine}

Lj. Marina, S. Vujovic, M. Ivovic, M. Tancic-Gajic, Z. Arizanovic, D. Rakovic, M. Zarkovic, T. Lalic, M. Djurovic-Nikolic, Z. Jemuovic, D. Micic

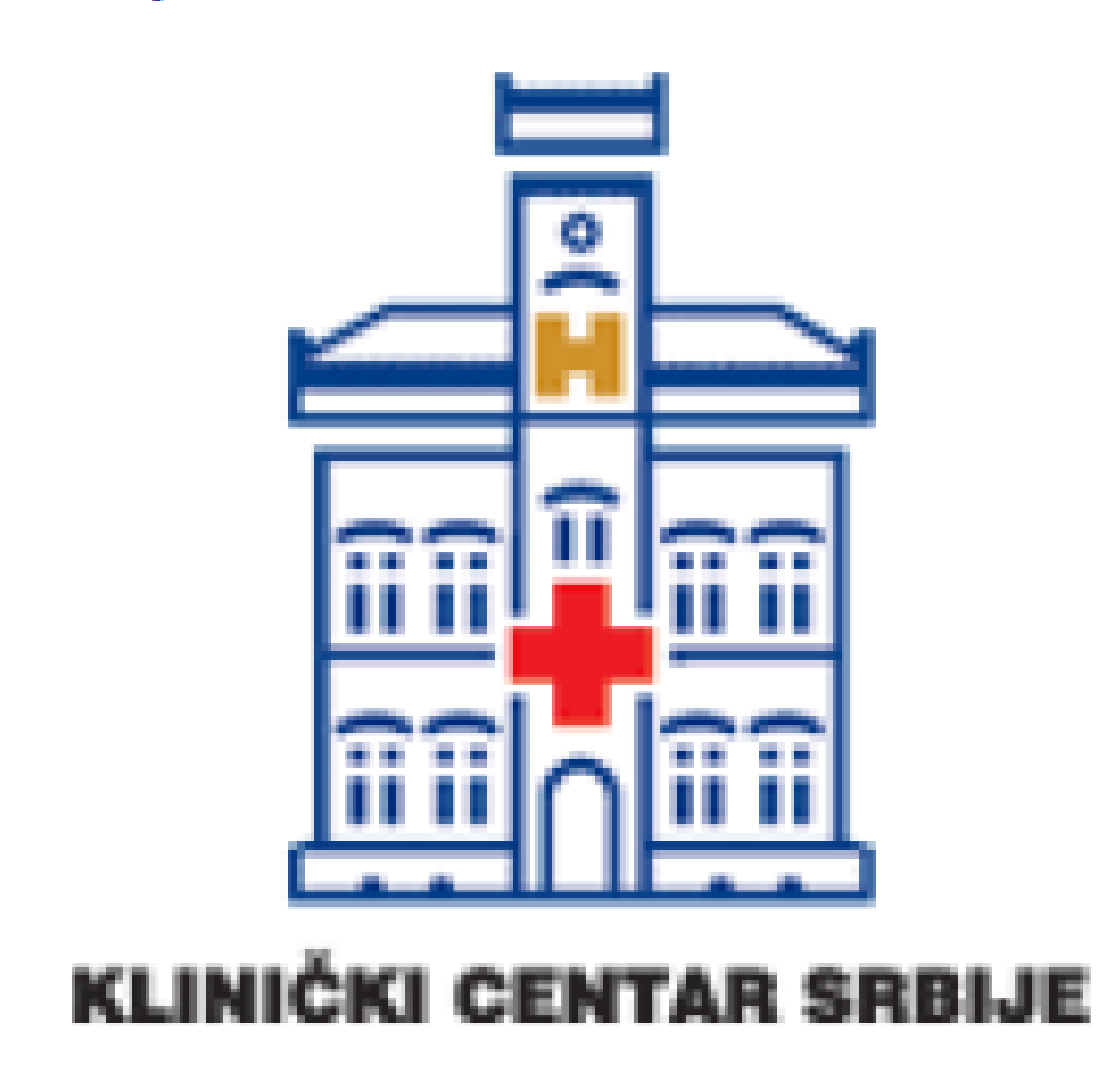

\section{Introduction}

Chronic fatigue syndrome is characterized by a state of chronic fatigue that persists for more than 6 months and has no clear cause.

\section{Case report}

A 38-year-old male was referred to our Clinic due to chronic fatigue, unrefreshing sleep, substantial impairment in concentration, headaches and postexertional malaise lasting from 6 to 9 months for 9 years.

As a mechanical engineer he was working in shifts $12 \mathrm{~h}$ day $/ 24 \mathrm{~h}$ break/12h night/72h break for 9 years. Other than allergy to penicillin he denied any significant health issues.

Complete blood count, liver and kidney function tests, basal gonadotropin, $\mathrm{TSH}$, prolactin, $\mathrm{ACTH}$, cortisol and testosterone levels were normal. Hepatitis B, C, HIV and anti nuclear antibodies were negative. Chest $X$ ray and abdominal ultrasound were normal. Psychiatrist excluded a psychiatric disorder.

Standard and $1 \mathrm{mcg}$ Synacthen test showed inadequate peak cortisol $419 \mathrm{nmol} / \mathrm{l}$ and $532 \mathrm{nmol} / \mathrm{l}$, respectively. $\diamond$ Glucose $\diamond$ ACTH $\diamond$ Cortisol $\diamond$ Growth hormone $\diamond$ Prolactin

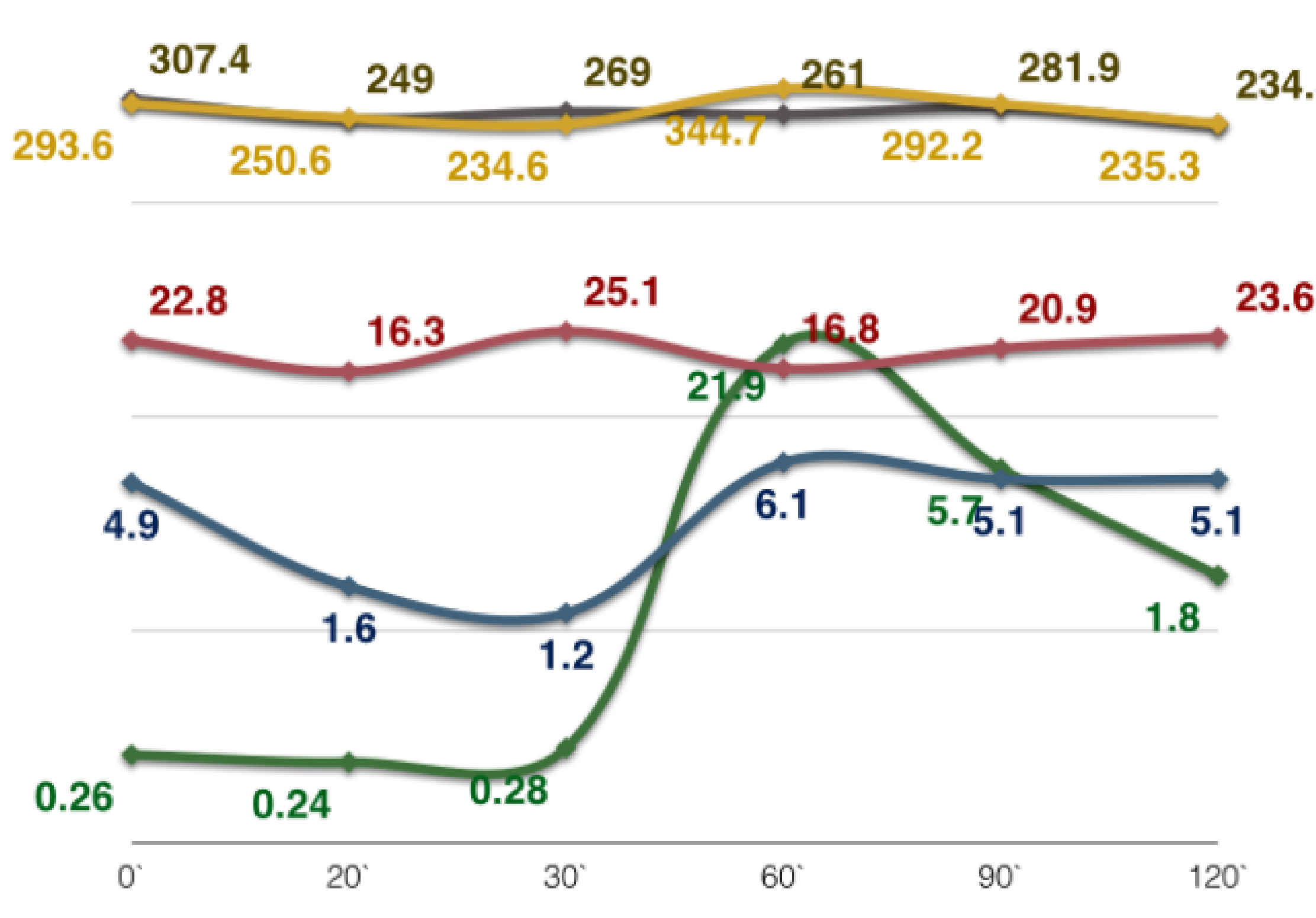

Insulin Tolerance Test

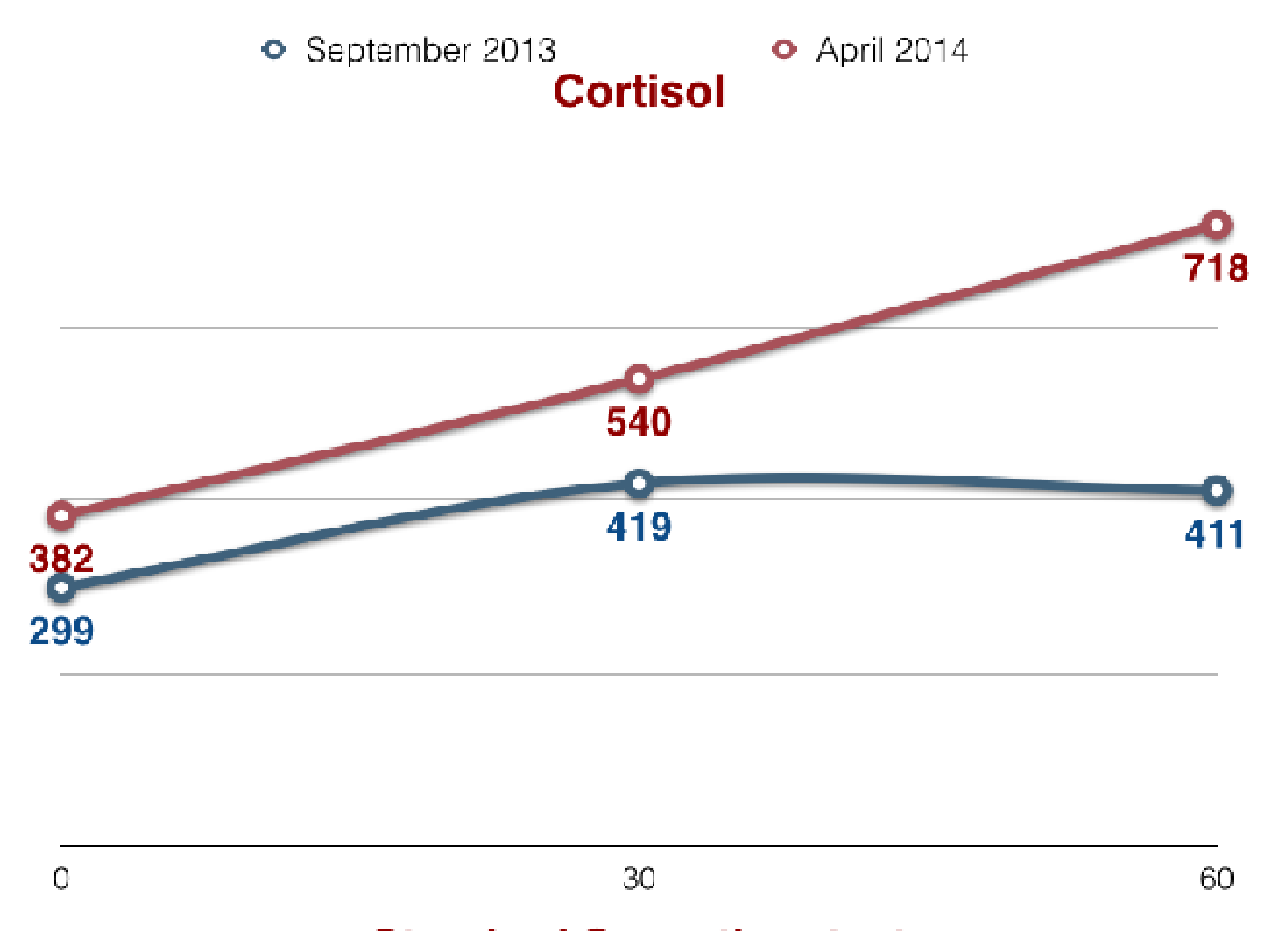

Standard Synacthen test
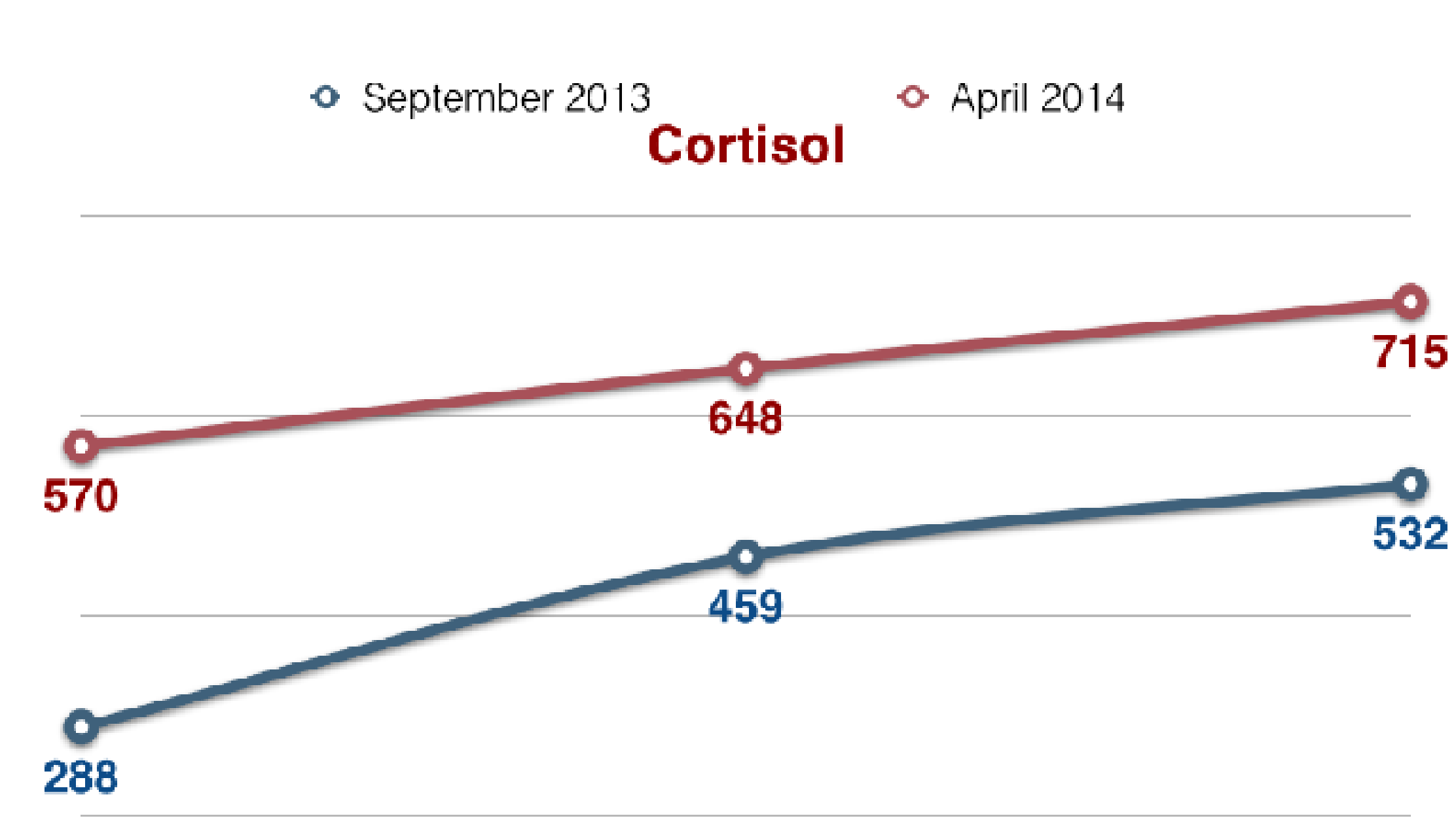

Low dose Synacthen test
Insulin tolerance test, with hypoglycemia of $1.2 \mathrm{mmol} / \mathrm{l}$ in $30^{\circ}$, showed inadequate peak responses of ACTH 25ng/L in 30, cortisol $345 \mathrm{nmol} / / \mathrm{I}$ in $60^{\circ}$, prolactin $282 \mathrm{mlU} / \mathrm{I}$ and low normal growth hormone $22 \mathrm{mIU} / \mathrm{L}$ in $60^{\circ}$.

Endocranium with hypothalamopituitary region MRI was normal.

The patient was diagnosed with chronic fatigue syndrome (CFS).

As we advised he stopped working in shifts and commenced a low-grade physical activity with cognitive behavioral therapy.

After 6 months he was complaint free with adequate cortisol levels in standard and $1 \mathrm{mcg}$ Synacthen test, $718 \mathrm{nmol} / \mathrm{l}$ and $715 \mathrm{nmol} / \mathrm{l}$, respectively. After a year he was still complaint free with basal cortisol 570nmol/l.

\section{Conclusion}

The cause of CFS in our patient was the long-term exposure to a stressor shift work, which led to a circadian disruption, crashing adaptive mechanisms and leading to a disease. 